\title{
MicroRNA in Papillary Thyroid Carcinoma: A Systematic Review from 2018 to June 2020
}

\author{
Liviu Hitu ${ }^{1, *(1)}$, Katalin Gabora ${ }^{1}$, Eduard-Alexandru Bonci ${ }^{1}{ }^{(\mathbb{D}}$, Andra Piciu ${ }^{2}{ }^{(D}$, \\ Adriana-Cezara Hitu ${ }^{3}$, Paul-Andrei Stefan ${ }^{1,4}$ (i) and Doina Piciu ${ }^{1,5}$
}

1 Doctoral School, Iuliu Hațieganu University of Medicine and Pharmacy, 400012 Cluj-Napoca, Romania; gabora.katalin@yahoo.com (K.G.); bonci.eduard@gmail.com (E.-A.B.); stefan_paul@ymail.com (P.-A.Ș.); doina.piciu@gmail.com (D.P.)

2 Department of Medical Oncology, Iuliu Hatieganu University of Medicine and Pharmacy, 400012 Cluj-Napoca, Romania; piciuandra@gmail.com

3 Department of Dermatology, Iuliu Hatieganu University of Medicine and Pharmacy, 400012 Cluj-Napoca, Romania; cezara.lala@gmail.com

4 Radiology and Imaging Department, County Emergency Hospital, Cluj-Napoca, Clinicilor Street, Number 3-5, Cluj-Napoca, 400006 Cluj, Romania

5 Department of Endocrine Tumors and Nuclear Medicine, Institute of Oncology "Prof.dr.Ion Chiricut, ă" 400015 Cluj-Napoca, Romania

* Correspondence: Liviu.Hitu@umfcluj.ro

Received: 9 September 2020; Accepted: 21 October 2020; Published: 25 October 2020

Simple Summary: The most common form of endocrine cancer - papillary thyroid carcinoma, has an increasing incidence. Although this disease usually has an indolent behavior, there are cases when it can evolve more aggressively. It has been known for some time that it is possible to use microRNAs for the diagnosis, prognosis and even treatment monitoring of papillary thyroid cancer. The purpose of this study is to summarize the latest information provided by publications regarding the involvement of microRNAs in papillary thyroid cancer, underling the new clinical perspectives offered by these publications.

Abstract: The involvement of micro-ribonucleic acid (microRNAs) in metabolic pathways such as regulation, signal transduction, cell maintenance, and differentiation make them possible biomarkers and therapeutic targets. The purpose of this review is to summarize the information published in the last two and a half years about the involvement of microRNAs in papillary thyroid carcinoma (PTC). Another goal is to understand the perspective offered by the new findings. Main microRNA features such as origin, regulation, targeted genes, and metabolic pathways will be presented in this paper. We interrogated the PubMed database using several keywords: "microRNA" + "thyroid" + "papillary" + "carcinoma". After applying search filters and inclusion criteria, a selection of 137 articles published between January 2018-June 2020 was made. Data regarding microRNA, metabolic pathways, gene/protein, and study utility were selected and included in the table and later discussed regarding the matter at hand. We found that most microRNAs regularly expressed in the normal thyroid gland are downregulated in PTC, indicating an important tumor-suppressor action by those microRNAs. Moreover, we showed that one gene can be targeted by several microRNAs and have nominally described these interactions. We have revealed which microRNAs can target several genes at once.

Keywords: microRNA; miRNA; papillary; thyroid; carcinoma; microcarcinoma 


\section{Introduction}

Given that in the last two and a half years alone, more than 200 articles have been published on the involvement of microRNAs in the pathology of PTC, microRNAs are a hot topic. Several questions arise from the analysis of these studies, for example, how relevant is the information of these studies to daily medical practice; Will this information ever be beneficial for the patients with an aggressive form of papillary carcinoma? Or we design studies on the treadmill pursuing only scientific interest? During the 1970s, Francis Crick asserted what he believed to be the central dogma of molecular biology. Genetic information traveled from deoxyribonucleic acid (DNA) to ribonucleic acid (RNA) through transcription, then from RNA to proteins via translation, meaning proteins were the functional end products of genes. However, after the whole human genome sequencing, it was understood that genes that encoded proteins accounted for less than $2 \%$ of the genome. Given the intricacy of cellular processes, genetic information is most likely passed by additional regulatory elements and not only by coding genes [1]. MicroRNAs (miRNAs) are a class of endogenous non-coding RNA molecules ranging from 18 to 22 nucleotides in length. MicroRNA's constitute only 3\% of the human genome but it is believed that they regulate more than half of the protein-coding genes. Mature microRNA can promote or inhibit messenger ribonucleic acid (mRNA) translation and degradation by targeting with precision complementary sequences in $3^{\prime}$ UnTranslated Regions ( $3^{\prime}$ UTR). They act both as post-transcriptional regulators of gene expression and as messengers or intercellular signaling [2]. MicroRNAs are involved in central biological processes, including development, organogenesis, tissue differentiation, cell cycles, and metabolism. Alterations in the expression of microRNA contribute to the pathogenesis of the majority of human malignancies (PTC) [3,4]. The most striking evidence that links microRNAs with thyroid cancer is their large alteration in expression in malignant cells compared to benign cells. MicroRNA expression is dysregulated in human cancer through various mechanisms. The most important are amplification or deletion of microRNA genes, abnormal transcriptional control of microRNAs, and epigenetic changes [5]. PTC is the most common thyroid malignancy [6], and it is defined as a malignant epithelial tumor with evidence of follicular differentiation and a series of specific nuclear features [7]. The incidence of PTC is increasing mainly due to improved diagnostic methods such as ultrasound (US) with targeted fine-needle aspiration biopsy (FNAB) [8]. This increase has been predominantly an increase in diagnosing papillary thyroid microcarcinoma (PTMC). PTMC is defined as measuring $1.0 \mathrm{~cm}$ or less in the greatest dimension of the tumor [9]. Cervical lymph nodes, lungs, and bones are the most common metastatic sites, brain, liver, and skin involvement is less common. Distant metastases are usually diagnosed through clinical symptoms or suspicious imaging/laboratory findings (abnormal uptake on the post-ablation whole-body scan (WBS). Another diagnostic method can be a positive finding on an F18-fluorodeoxyglucose (F18-FDG) positron emission tomography/computed tomography (PET/CT) evaluation or cross-sectional study prompted by elevated thyroglobulin levels in patients whose post-ablation WBS is negative [10]. Usually, PTC has an excellent prognosis [11]. Therefore, what are the special situations in daily practice that make us need these new potential biological markers for PTC diagnosis, prognosis, and therapeutic targets? The purpose of this review is to summarize the information published in the last two and a half years about the involvement of microRNAs in PTC. It is also to understand the perspective offered by the new findings.

\section{Materials and Methods}

A literature analysis was performed in MEDLINE using PubMed for studies published from 2018 to June 2020. The following keywords were used: "microRNA" + "papillary" + "thyroid" + "carcinoma", which resulted in 466 articles in English. All related abstracts were reviewed and relevant studies that were published in English were selected. We only included papers that had full text available and described the exact method and results regarding microRNA's signatures in PTC epigenetic mechanism. A selection of 137 eligible articles was the result of our search (Figure 1). 


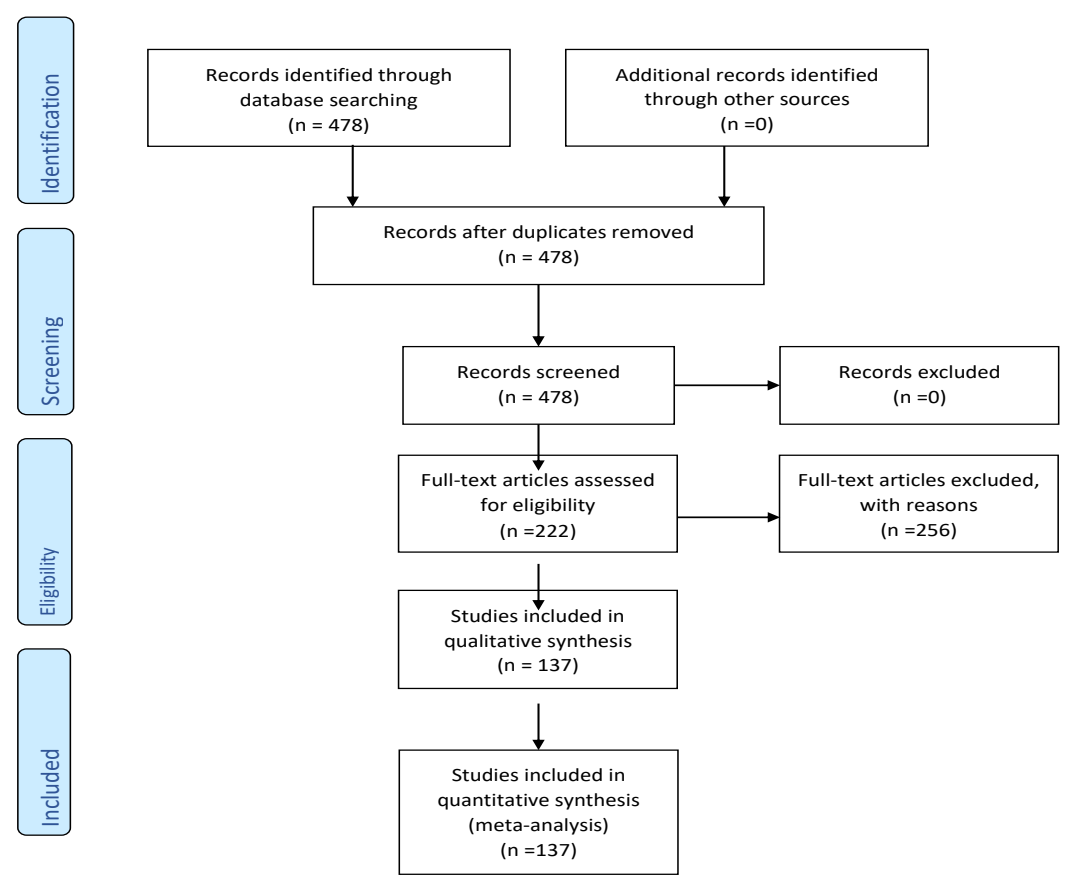

Figure 1. Study selection summary.

\section{Results}

Data on microRNAs, the sample source, the regulatory mode of microRNAs, the target genes/proteins of microRNAs, and their effect on PTC cells from the 137 studies were selected and presented in Table 1 [12-148]. 
Table 1. Targets of epigenetic alterations in papillary thyroid carcinoma (PTC).

\begin{tabular}{|c|c|c|c|c|c|c|c|}
\hline miRNA & $\begin{array}{l}\text { Sample } \\
\text { Sources }\end{array}$ & $\begin{array}{l}\text { Up/Down- } \\
\text { Regulated }\end{array}$ & $\begin{array}{l}\text { Targeted } \\
\text { Gene }\end{array}$ & miRNA Effect on PTC Cells & $\begin{array}{c}\text { Sponging/ } \\
\text { Sequestering }\end{array}$ & $\begin{array}{c}\text { Potential } \\
\text { Utility }\end{array}$ & References \\
\hline miR-520a-3p & tissue & Down & JAK1 & $\begin{array}{c}\text { prevented cell proliferation, migration, invasion, } \\
\text { promoted apoptosis }\end{array}$ & & $\mathrm{TT}$ & Bi. CL et al. [12] \\
\hline miR-139-5p & tissue & Down & LMO4 & suppressed cell proliferation, migration, and tumor growth & circBACH2 & Pr, TT & Cai. $X$ et al. [13] \\
\hline $\operatorname{miR}-128$ & tissue & Down & SPHK1 & $\begin{array}{l}\text { elevated apoptosis increased G0/G1 arrest, reduced Cyclin D1/ } \\
\text { CDK4 expressions }\end{array}$ & - & $\mathrm{TT}$ & Cao. XZ et al. [14] \\
\hline miR-2861 & tissue & Up & DGCR5 & promoted cell proliferation and invasion & lncRNA DGCR5 & $\mathrm{Pg}$ & Chen. F et al. [15] \\
\hline $\operatorname{miR}-101$ & tissue & Down & CXCL12 & $\begin{array}{l}\text { repressed cell proliferation, migration, and invasion. } \\
\text { Enhanced apoptosis }\end{array}$ & - & $\mathrm{Pg}, \mathrm{TT}$ & Chen. F et al. [16] \\
\hline miR-135b-5p & tissue & Up & CCNG2 & modulated tumor cells proliferation, apoptosis, migration & $\begin{array}{l}\text { lncRNA } \\
\text { GAS8-AS1 }\end{array}$ & $\mathrm{TT}$ & Chen. $\mathrm{N}$ et al. [17] \\
\hline miR-202-3p & tissue & Down & WNT & $\begin{array}{c}\text { suppressed the expression of } \beta \text {-catenin, cell migration, } \\
\text { and invasion }\end{array}$ & - & $\mathrm{TT}$ & Chen. J et al. [18] \\
\hline miR-1271 & tissue & Up & IRS1 & suppressed migration, invasion, and proliferation of PTC cells & - & $\mathrm{TT}$ & Chen. Y et al. [19] \\
\hline miR-153-3p & tissue & Down & ZNRF2 & regulated cell proliferation, migration, and invasion & lncRNA TTN-AS1 & TT & Cui. Z et al. [20] \\
\hline $\operatorname{miR}-548 c-3 p$ & tissue & Down & $\mathrm{HIF} 1 \alpha$ & reducted $\mathrm{N}$-cadherin and vimentin expression & - & $\mathrm{Pg}, \mathrm{TT}$ & Du. Y et al. [21] \\
\hline $\operatorname{miR}-150$ & tissue & Down & MUC4 & suppressed PTC cell proliferation and metastasis & - & $\mathrm{Dg}, \mathrm{TT}$ & Fa. Z et al. [22] \\
\hline Ex-miR-103 & blood & Up & GPER1 & influenced the differentiation of CD4 + T cell into Treg cells & - & TT & Fang. T et al. [23] \\
\hline $\operatorname{miR}-625-3 p$ & tissue & Up & AEG-1 & $\begin{array}{l}\text { promoted the proliferation, migration, and invasion of thyroid } \\
\text { cancer cells }\end{array}$ & - & $\mathrm{TT}$ & Fang. L et al. [24] \\
\hline miR-141-3p & tissue & Down & YY-1 & $\begin{array}{l}\text { inhibited cell growth, induced apoptosis, } \\
\text { and suppressed invasion }\end{array}$ & - & $\mathrm{Pg}, \mathrm{TT}$ & Fang. M et al. [25] \\
\hline miR-613 & tissue & Down & SphK2 & inhibited cell proliferation, migration, and invasion & $\begin{array}{l}\text { lncRNA } \\
\text { LINC00460 }\end{array}$ & $\mathrm{TT}$ & Feng. L et al. [26] \\
\hline miR-93-3p-660 & tissue & Up & FOXO1 & $\begin{array}{l}\text { inhibited glycolysis that attenuated glucose uptake and } \\
\text { lactate production }\end{array}$ & $\begin{array}{c}\text { lncRNA } \\
\text { ASMTL-AS1 }\end{array}$ & TT & Feng. Z et al. [27] \\
\hline miR-1266 & tissue & Down & FGFR2 & inhibited PTC cell proliferation, migration, and invasion & - & $\mathrm{Dg}, \mathrm{TT}$ & Fu. YT et al. [28] \\
\hline $\operatorname{miR}-129$ & tissue & Up & MAL2 & suppressed growth and invasion of PTC cells & - & $\mathrm{Pv}, \mathrm{TT}$ & Gao. X et al. [29] \\
\hline $\operatorname{miR}-791$ & tissue & Down & - & inhibited proliferation of PTC cells via blocking the G1 phase & - & $\mathrm{Pg}, \mathrm{TT}$ & Gao. XB et al. [30] \\
\hline
\end{tabular}


Table 1. Cont

\begin{tabular}{|c|c|c|c|c|c|c|c|}
\hline miRNA & $\begin{array}{l}\text { Sample } \\
\text { Sources }\end{array}$ & $\begin{array}{l}\text { Up/Down- } \\
\text { Regulated }\end{array}$ & $\begin{array}{l}\text { Targeted } \\
\text { Gene }\end{array}$ & miRNA Effect on PTC Cells & $\begin{array}{c}\text { Sponging/ } \\
\text { Sequestering }\end{array}$ & $\begin{array}{c}\text { Potential } \\
\text { Utility }\end{array}$ & References \\
\hline $\operatorname{miR}-429$ & tissue & Down & ZEB1 & inhibited cell proliferation, migration, and invasion & lncRNA SNHG22 & $\mathrm{Dg}, \mathrm{TT}$ & Gao. H et al. [31] \\
\hline miR-30a & tissue & Down & E2F7 & $\begin{array}{l}\text { inhibited the proliferation, migration, and invasion of } \\
\text { PTC cells }\end{array}$ & - & TT & Guo. H et al. [32] \\
\hline $\operatorname{miR}-9-5 p$ & tissue & Down & BRAF & $\begin{array}{l}\text { suppressed the viability of PTC cells by } \\
\text { inducing apoptosis }\end{array}$ & - & $\mathrm{TT}$ & Guo. F et al. [33] \\
\hline miR-215 & tissue & Down & ARFGEF1 & inhibited proliferation and metastasis & - & $\mathrm{Pg}$ & Han. J et al. [34] \\
\hline Ex-miR-199 & blood & Down & DLG1-AS1 & suppressed proliferation of PTC cells & - & $\mathrm{Dg}$ & He. T et al. [35] \\
\hline miR-1252 & tissue & Up & FSTL1 & $\begin{array}{c}\text { inhibited viability, proliferation, and stimulated } \\
\text { apoptosis in PTC cells. }\end{array}$ & hsa_circ_ 0011290 & TT & Hu. Z et al. [36] \\
\hline miR-486-5p & tissue & Down & KIAA1199 & inhibited cell growth of PTC & - & $\mathrm{TT}$ & Jiao. X et al. [37] \\
\hline miR-885-5p & tissue & Down & RAC1 & suppressed PTC cell proliferation & hsa_circ_ 0004458 & $\mathrm{TT}$ & Jin. $X$ et al. [38] \\
\hline $\operatorname{miR}-15 a$ & tissue & Down & RET/AKT & $\begin{array}{l}\text { inhibited PTC cell proliferation and invasion and } \\
\text { enhanced the apoptosis }\end{array}$ & - & $\mathrm{TT}$ & Jin. J et al. [39] \\
\hline miR-381-3p & tissue & Down & LRP6 & inhibited the proliferation and metastasis of PTC cells & - & TT & Kong. $\mathrm{W}$ et al. [40] \\
\hline $\operatorname{miR}-485-5 p$ & tissue & Down & Raf1 & inhibited PTC cell proliferation, migration and invasion & $\begin{array}{l}\text { LncRNA } \\
\text { LINC00460 }\end{array}$ & $\mathrm{TT}$ & Li. G et al. [41] \\
\hline miR-320a & cell culture & Up & HMGB1 & inhibited cell proliferation, migration and invasion rates & IncRNA ANRIL & $\mathrm{Pv}, \mathrm{TT}$ & Li. M et al. [42] \\
\hline miR-369-3p & cell culture & Down & TSPAN13 & $\begin{array}{l}\text { suppressed cell proliferation, colony formation, } \\
\text { and induced apoptosis in PTC }\end{array}$ & - & $\mathrm{Dg}, \mathrm{Pv}, \mathrm{TT}$ & Li. P et al. [43] \\
\hline miR-205 & tissue & Down & YAP1 & $\begin{array}{l}\text { inhibited proliferation and invasion of thyroid } \\
\text { cancer cells }\end{array}$ & - & $\mathrm{TT}$ & Li. D et al. [44] \\
\hline miR-204-3p & tissue & Down & CDC23 & suppressed PTC proliferation, migration and invasion & $\begin{array}{l}\text { lncRNA } \\
\text { LINC00514 }\end{array}$ & $\mathrm{TT}$ & Li. X et al. [45] \\
\hline miR-361-5p & tissue & Down & ROCK1 & Inhibited proliferation, migration, and invasion & - & $\mathrm{TT}$ & Li. R et al. [46] \\
\hline $\operatorname{miR}-4500$ & cell culture & Down & PLXNC1 & $\begin{array}{l}\text { inhibited cell viability, colony formation, } \\
\text { and cell apoptosis }\end{array}$ & - & $\mathrm{Pg}, \mathrm{TT}$ & Li. R et al. [47] \\
\hline miR-211-5p & tissue & Down & SPARC & $\begin{array}{l}\text { suppressed proliferation, migration, and invasion of } \\
\text { thyroid tumor cells }\end{array}$ & $\begin{array}{c}\text { lncRNA } \\
\text { MCM3AP-AS1 }\end{array}$ & TT & Liang. $\mathrm{M}$ et al. [48] \\
\hline miR-101 & tissue & Down & FN1 & promoted the RAI-resistance in PTC & lncRNA-NEAT1 & TT & Liu. C et al. [49] \\
\hline
\end{tabular}


Table 1. Cont

\begin{tabular}{|c|c|c|c|c|c|c|c|}
\hline miRNA & $\begin{array}{l}\text { Sample } \\
\text { Sources }\end{array}$ & $\begin{array}{l}\text { Up/Down- } \\
\text { Regulated }\end{array}$ & $\begin{array}{l}\text { Targeted } \\
\text { Gene }\end{array}$ & miRNA Effect on PTC Cells & $\begin{array}{l}\text { Sponging/ } \\
\text { Sequestering }\end{array}$ & $\begin{array}{l}\text { Potential } \\
\text { Utility }\end{array}$ & References \\
\hline $\operatorname{miR}-214$ & tissue & Down & PSMD10 & $\begin{array}{l}\text { suppressed proliferation, and induced cell apoptosis } \\
\text { and cell cycle arrest in PTC cells }\end{array}$ & - & TT & Liu. F et al. [50] \\
\hline miR-744 & tissue & Down & NOB1 & attenuated the proliferation and invasion of PTC cells & - & TT & Liu. H et al. [51] \\
\hline $\operatorname{miR}-96-5 p$ & tissue & Up & CCDC67 & accelerated the proliferation and metastasis of PTC cells & - & $\mathrm{Dg}, \mathrm{TT}$ & Liu. ZM et al. [52] \\
\hline $\operatorname{miR}-4728$ & cell culture & Down & SOS1 & repressed the PTC cell proliferation through MAPK & - & $\mathrm{Dg}, \mathrm{TT}$ & Liu. Z et al. [53] \\
\hline $\operatorname{miR}-431$ & tissue & Down & Gli1 & inhibited cell migration and invasion of PTC & - & TT & Liu. Y et al. [54] \\
\hline miR-524-5p & tissue & Down & $\begin{array}{l}\text { FOXE1, } \\
\text { ITGA3 }\end{array}$ & $\begin{array}{l}\text { suppressed PTC progression by regulating tumor cell } \\
\text { proliferation, migration, and invasion }\end{array}$ & - & TT & Liu. H et al. [55] \\
\hline $\operatorname{miR}-331-3 p$ & tissue & Down & SLC25A1 & $\begin{array}{l}\text { inhibited PTC cells proliferation, migration } \\
\text { and invasion }\end{array}$ & lncRNA-BRM & TT & Liu. S et al. [56] \\
\hline miR-335-5p & tissue & Down & ICAM1 & reduced the proliferation, migration, invasion of PTC & - & TT & Luo. L et al. [57] \\
\hline miR-146a & tissue & - & GABPA & $\begin{array}{l}\text { suppressed proliferation, migration, and invading } \\
\text { capabilities of PTC cells }\end{array}$ & & TT & Long. $\mathrm{M}$ et al. [58] \\
\hline miR-29a-3p & tissue & Down & OTUB2 & suppressed growth, proliferation, invasion in PTC cells. & - & $\mathrm{Pg}, \mathrm{TT}$ & Ma. Y et al. [59] \\
\hline miR-199a-5p & tissue & Down & SNAI1 & reduced migration and invasion of PTC cells & - & TT & Ma. S et al. [60] \\
\hline miR-363-3p & tissue & Down & ITGA6 & suppressed anoikis resistance in PTC cells & - & TT & Pan. Y et al. [61] \\
\hline $\begin{array}{l}\text { miR-1231, } \\
\text { miR-1304 }\end{array}$ & tissue & Down & - & inhibited proliferation and invasion of PTC cells & circ_ 0025033 & TT & Pan. Y et al. [62] \\
\hline miR-146b-5p & tissue & Up & DNMT3A & $\begin{array}{l}\text { accelerated extra-glandular invasion and metastasis of } \\
\text { PTC cells }\end{array}$ & lncRNA-MALAT1 & $\mathrm{Dg}, \mathrm{TT}$ & Peng. Y et al. [63] \\
\hline $\operatorname{miR}-448$ & tissue & Down & KDM5B & $\begin{array}{l}\text { inhibited PTC cell progression and tumor growth } \\
\text { via TGIF1 }\end{array}$ & - & TT & Pu. Y et al. [64] \\
\hline miR-199b-5p & tissue & Down & STON2 & inhibited PTC cell growth and metastasis & - & TT & Ren. L et al. [65] \\
\hline miR-26a-5p & tissue & Down & Wnt5a & $\begin{array}{l}\text { inhibited proliferation, colony formation, invasion, } \\
\text { and migration of PTC cells. }\end{array}$ & - & TT & Shi. D et al. [66] \\
\hline $\operatorname{miR}-564$ & tissue & Down & AEG-1 & $\begin{array}{l}\text { inhibited cell proliferation, migration, and invasion and } \\
\text { induced cell apoptosis }\end{array}$ & - & TT & Song. Z et al. [67] \\
\hline miR-214-3p & tissue & Down & PSMD10 & impaired PTC cell proliferation and metastasis & lncRNA-SNHG3 & TT & Sui. G et al. [68] \\
\hline
\end{tabular}


Table 1. Cont

\begin{tabular}{|c|c|c|c|c|c|c|c|}
\hline miRNA & $\begin{array}{l}\text { Sample } \\
\text { Sources }\end{array}$ & $\begin{array}{l}\text { Up/Down- } \\
\text { Regulated }\end{array}$ & $\begin{array}{l}\text { Targeted } \\
\text { Gene }\end{array}$ & miRNA Effect on PTC Cells & $\begin{array}{l}\text { Sponging/ } \\
\text { Sequestering }\end{array}$ & $\begin{array}{c}\text { Potential } \\
\text { Utility }\end{array}$ & References \\
\hline miR-144 & tissue & Down & WWTR1 & inhibited of PTC cell proliferation & - & $\mathrm{Pg}, \mathrm{TT}$ & Sun. W et al. [69] \\
\hline miR-106b-5p & tissue & Down & ATAD2 & induced apoptosis and suppressed invasion of PTC cells & lncRNA-NEAT1_2 & TT & Sun. W et al. [70] \\
\hline miR-124-3p & cell culture & Down & MAP2K4 & $\begin{array}{l}\text { inhibited the proliferation, induced apoptosis and cell cycle } \\
\text { arrest in PTC cells }\end{array}$ & - & TT & Sun. Y et al. [71] \\
\hline miR-577 & tissue & Down & Sphk2 & inhibited PTC cell proliferation, migration, and invasion & lncRNA-LINC00520 & $\mathrm{Dg}, \mathrm{TT}$ & Sun. Y et al. [72] \\
\hline $\operatorname{miR}-486$ & tissue & Down & TENM1 & inhibited proliferation, invasion, and migration of PTC cell & - & TT & Sun. YH et al. [73] \\
\hline $\operatorname{miR}-497$ & tissue & Down & BDNF & suppressed PTC cell proliferation, migration, and invasion & lncRNA-LINC00152 & TT & Sun. Z et al. [74] \\
\hline miR-22 & tissue & Up & - & promoted PTC cell metastasis and BRAFV600E mutation & - & $\mathrm{Dg}, \mathrm{Pg}$ & Wang. D et al. [75] \\
\hline miR-599 & tissue & Down & Hey2 & $\begin{array}{c}\text { diminished PTC cell proliferation, migration, invasion, } \\
\text { while stimulating apoptosis }\end{array}$ & - & Pr, TT & Wang. DP et al. [76] \\
\hline miR-3619-5p & cell culture & Down & FOXM1 & regulated proliferation and apoptosis in PTC & lncRNA-Linc01410 & TT & Wang. G et al. [77] \\
\hline miR-675 & tissue & Down & MAPK1 & suppressed PTC cell proliferation, migration, and invasion & lncRNA-RMRP & TT & Wang. J et al. [78] \\
\hline miR-1258 & cell culture & Down & TMPRSS4 & inhibited cell viability, migration, and invasion & - & $\mathrm{Dg}, \mathrm{TT}$ & Wang. L et al. [79] \\
\hline miR-451a & tissue & Down & ZEB1 & suppressed proliferation, mobility, and invasion of PTC cell & - & TT & Wang. Q et al. [80] \\
\hline $\operatorname{miR}-622$ & tissue & Down & VEGFA & inhibited PTC cell proliferation, migration, and invasion & - & TT & Wang. R et al. [81] \\
\hline $\operatorname{miR}-212$ & tissue & Down & MIAT & inhibited PTC cell proliferation, migration, and invasion. & $\begin{array}{c}\text { (possible) } \\
\text { lncRNA-MIAT }\end{array}$ & TT & Wang. R et al. [82] \\
\hline miR-718 & tissue & Down & PDPK1 & $\begin{array}{l}\text { inhibited PTC cell growth, reduced cell invasion, repressed } \\
\text { glucose metabolism }\end{array}$ & - & $\mathrm{Dg}, \mathrm{TT}$ & Wang. X et al. [83] \\
\hline miR-31 & tissue & Down & SOX11 & repressed PTC cell proliferation, invasion, and migration & - & TT & Wang. Y et al. [84] \\
\hline $\operatorname{miR}-384$ & tissue & Down & PRKACB & suppressed PTC cell proliferation and migration & - & TT & Wang. Y et al. [85] \\
\hline $\operatorname{miR}-873$ & tissue & Down & CXCL16 & $\begin{array}{l}\text { inhibited proliferation, migration, and invasion of the } \\
\text { PTC cells }\end{array}$ & - & TT & Wang. Z et al. [86] \\
\hline miR-143-3p & tissue & Down & MSI2 & $\begin{array}{c}\text { induced apoptosis, suppresses invasion and migration } \\
\text { of PTC }\end{array}$ & - & TT & Wang. ZL et al. [87] \\
\hline
\end{tabular}


Table 1. Cont

\begin{tabular}{|c|c|c|c|c|c|c|c|}
\hline miRNA & $\begin{array}{l}\text { Sample } \\
\text { Sources }\end{array}$ & $\begin{array}{l}\text { Up/Down- } \\
\text { Regulated }\end{array}$ & $\begin{array}{l}\text { Targeted } \\
\text { Gene }\end{array}$ & miRNA Effect on PTC Cells & $\begin{array}{c}\text { Sponging/ } \\
\text { Sequestering }\end{array}$ & $\begin{array}{c}\text { Potential } \\
\text { Utility }\end{array}$ & References \\
\hline miR-1261 & tissue & Down & C8orf4 & inhibited PTC cell proliferation, migration, and invasion & circZFR & TT & Wei. H et al. [88] \\
\hline miR-200a-3p & tissue & Down & YAP1 & inhibited PTC cell proliferation and promoted apoptosis & lncRNA-SNHG15 & TT & Wu. DM et al. [89] \\
\hline miR-329 & tissue & Down & WNT1 & $\begin{array}{l}\text { decreased PTC cell proliferation, colony formation, } \\
\text { suppressed growth }\end{array}$ & - & TT & Wu. L et al. [90] \\
\hline miR-203 & tissue & Down & Bcl-2 & $\begin{array}{l}\text { inhibited cell proliferation, induced apoptosis, } \\
\text { and suppressed the motility of PTC cells }\end{array}$ & - & TT & Wu. X et al. [91] \\
\hline miR-26a & tissue & Down & ROCK1 & repressed PTC cell viability, invasion, and metastasis & - & $\mathrm{Dg}, \mathrm{TT}$ & Wu. YC et al. [92] \\
\hline miR-222 & tissue & Up & - & $\begin{array}{c}\text { correlated with capsular invasion, vascular invasion, } \\
\text { tumor size and metastasis }\end{array}$ & - & $\mathrm{Pg}$ & Xiang. D et al. [93] \\
\hline miR-150-5p & cell culture & Up & BRAF(V600E) & promoted PTC cell proliferation, suppressed apoptosis & - & TT & Yan. R et al. [94] \\
\hline miR-423-5p & cell culture & Down & SOX12 & suppressed PTC cell proliferation and invasion & lncRNA-NR2F1-AS1 & TT & Yang. C et al. [95] \\
\hline miR-182 & tissue & Up & $\mathrm{CHL}^{*}$ * & $\begin{array}{c}\text { correlated with extrathyroidal invasion, cervical lymph } \\
\text { node metastasis, and TNM }\end{array}$ & - & $\mathrm{Pg}$ & Yao. XG et al. [96] \\
\hline miR-1179 & tissue & - & HMGB1 & - & circFOXM1 & TT & Ye. M et al. [97] \\
\hline $\operatorname{miR}-1270$ & cell culture & $\mathrm{Up}$ & SCAI & promoted PTC cell proliferation, migration & - & $\mathrm{TT}$ & Yi. T et al. [98] \\
\hline miR-761 & tissue & Down & TRIM29 & $\begin{array}{l}\text { inhibited cell proliferation, and cell cycle progression } \\
\text { in PTC }\end{array}$ & $\begin{array}{l}\text { lncRNA- } \\
\text { HOXA11-AS }\end{array}$ & $\mathrm{TT}$ & Yin. X et al. [99] \\
\hline miR-23a- & tissue & Down & CCNG1 & $\begin{array}{l}\text { decreased proliferation, induced cell cycle arrest, } \\
\text { and promoted PTC cell apoptosis }\end{array}$ & - & $\mathrm{Dg}, \mathrm{TT}$ & Yin. JJ et al. [100] \\
\hline miR-203 & tissue & Down & AKT3 & $\begin{array}{l}\text { suppressed cell migration and invasion in the PTC cells } \\
\text { and promoted cell apoptosis }\end{array}$ & - & TT & You. A et al. [101] \\
\hline miR-3619-3p & tissue & $\mathrm{Up}$ & Wnt & promoted PTC cell migration and invasion & - & $\mathrm{TT}$ & Yu. S et al. [102] \\
\hline $\operatorname{miR}-637$ & tissue & Down & Akt1 & $\begin{array}{l}\text { inhibit inhibited PTC cell proliferation, invasion, } \\
\text { and migration }\end{array}$ & lncRNA HOTTIP & $\mathrm{Dg}, \mathrm{TT}$ & Yuan. Q et al. [103] \\
\hline miR-21 & tissue & $\mathrm{Up}$ & VHL & promoted PTC cell proliferation and invasion & - & TT & Zang. C et al. [104] \\
\hline
\end{tabular}


Table 1. Cont.

\begin{tabular}{|c|c|c|c|c|c|c|c|}
\hline miRNA & $\begin{array}{l}\text { Sample } \\
\text { Sources }\end{array}$ & $\begin{array}{l}\text { Up/Down- } \\
\text { Regulated }\end{array}$ & $\begin{array}{l}\text { Targeted } \\
\text { Gene }\end{array}$ & miRNA Effect on PTC Cells & $\begin{array}{l}\text { Sponging/ } \\
\text { Sequestering }\end{array}$ & $\begin{array}{l}\text { Potential } \\
\text { Utility }\end{array}$ & References \\
\hline miR-224-5p & tissue & Up & EGR2 & $\begin{array}{l}\text { promoted PTC cell } \\
\text { migration, invasion }\end{array}$ & - & $\mathrm{Dg}, \mathrm{TT}$ & Zang. CS et al. [105] \\
\hline miR-509 & tissue & Down & PAX9 & $\begin{array}{l}\text { inhibited cell proliferation and invasion in papillary } \\
\text { thyroid carcinoma }\end{array}$ & - & TT & Zhang. S et al. [106] \\
\hline miR-766 & tissue & Down & IRS2 & inhibited proliferation of PTC cells & - & TT & Zhao. J et al. [107] \\
\hline miR-96-3p & tissue & Up & SDHB & increased the invasion and migration of PTC cells & & TT & Zhao. X et al. [108] \\
\hline miR-138-5p & tissue & Down & LRRK2 & inhibited PTC cell proliferation, apoptosis & $\begin{array}{c}\text { lncRNA } \\
\text { RP11-476D10.1 }\end{array}$ & TT & Zhao. Y et al. [109] \\
\hline miR-409-3p & tissue & Down & CCND2 & $\begin{array}{l}\text { negatively regulated PTC cell proliferation and cell } \\
\text { cycle progression }\end{array}$ & - & Pr, TT & Zhao. Z et al. [110] \\
\hline $\mathrm{miR}-200 \mathrm{~b} / \mathrm{c}$ & tissue & Down & Rap1b & inhibited PTC cell invasion, migration and growth & - & TT & Zhou. B et al. [111] \\
\hline miR-188-5p & tissue & Down & FGF-5* & suppressed PTC cells growth & - & TT & Zhou. P et al. [112] \\
\hline miR-506 & tissue & Down & IL17RD & $\begin{array}{l}\text { inhibited the proliferation, invasion, and migration } \\
\text { capacities of PTC cells }\end{array}$ & - & $\mathrm{Pg}, \mathrm{TT}$ & Zhu. J et al. [113] \\
\hline miR-146 & tissue & $\mathrm{Up}^{*}$ & KIT & promoted PTC cell proliferation and invasion * & lncRNA CTC & TT & Liao. B et al. [114] \\
\hline $\operatorname{miR}-1178$ & tissue & Up & TLR4 & $\begin{array}{l}\text { promoted cell proliferation and suppressed } \\
\text { cell apoptosis }\end{array}$ & circ_FNDC3B & TT & Wu. G et al. [115] \\
\hline miR-106a & tissue & Up & $\begin{array}{l}\text { PTEN/ } \\
\text { SFR4 }\end{array}$ & $\begin{array}{c}\text { enhanced PTC cell proliferative, migratory and } \\
\text { invasive abilities }\end{array}$ & lncRNA-HULC & TT & Yang. Z et al. [116] \\
\hline miR-335 & tissue & Down & SOX2 & $\begin{array}{l}\text { suppressed the proliferation, migration, and invasion of } \\
\text { PTC cells }\end{array}$ & lncRNA-LINC01510 & TT & Li. Q et al. [117] \\
\hline miR-199a-5p & tissue & Down & SLC1A5 & $\begin{array}{l}\text { attenuated proliferation, induced apoptosis, } \\
\text { and arrested cells in the G0/G1 phase }\end{array}$ & ABHD11-AS1 & $\mathrm{Dg}, \mathrm{TT}$ & Zhuang. X et al. [118] \\
\hline miR-145-5p & tissue & Down & AKT3 & inhibited proliferation, migration and invasion & lncRNA-n384546 & $\mathrm{Dg}, \mathrm{TT}$ & Feng. J et al. [119] \\
\hline $\operatorname{miR}-211$ & tissue & Up & RECK & $\begin{array}{l}\text { promoted tumor growth and increased tumor volume } \\
\text { in PTC cells }\end{array}$ & - & $\mathrm{Dg}, \mathrm{Pg}$ & Wei. ZL et al. [120] \\
\hline miR-206 & tissue & Down & MAP4K3 & $\begin{array}{l}\text { enhanced Euthyrox sensitivity in Euthyrox-resistant } \\
\text { PTC cells }\end{array}$ & - & TT & Liu. F et al. [121] \\
\hline $\operatorname{miR}-21-5 p$ & cell culture & Up & $\begin{array}{l}\text { TGFBI, } \\
\text { COL4A1 }\end{array}$ & $\begin{array}{l}\text { secreted by hypoxic PTC cells is a potent } \\
\text { pro-angiogenic factor }\end{array}$ & - & $\mathrm{Dg}, \mathrm{TT}$ & Wu. F et al. [122] \\
\hline Ex-miR-423-5p & blood & Up & - & promoted PTC cell migration and invasion & - & Dg, TT & Ye. W et al. [123] \\
\hline
\end{tabular}


Table 1. Cont

\begin{tabular}{|c|c|c|c|c|c|c|c|}
\hline miRNA & $\begin{array}{l}\text { Sample } \\
\text { Sources }\end{array}$ & $\begin{array}{l}\text { Up/Down- } \\
\text { Regulated }\end{array}$ & $\begin{array}{l}\text { Targeted } \\
\text { Gene }\end{array}$ & miRNA Effect on PTC Cells & $\begin{array}{c}\text { Sponging/ } \\
\text { Sequestering }\end{array}$ & $\begin{array}{l}\text { Potential } \\
\text { Utility }\end{array}$ & References \\
\hline $\mathrm{miR}-422 \mathrm{a}$ & tissue & Down & SP1 & suppressed PTC cells proliferation and metastasis & lncRNA-LINC00313 & TT & Yan. D et al. [124] \\
\hline miR-1301-3p & tissue & Down & STAT3 & $\begin{array}{l}\text { inhibited PTC cell proliferation, cell apoptosis } \\
\text {-accelerated }\end{array}$ & lncRNA-ABDH11-AS1 & TT & Wen. J et al. [125] \\
\hline miR-let-7a & tissue & Down & c-Myc & $\begin{array}{l}\text { suppressed PTC cell proliferation, migration, } \\
\text { and invasion }\end{array}$ & - & TT & Huang. J et al. [126] \\
\hline miR-let-7e & tissue & Down & HMGB1 & inhibited of PTC cell growth and metastasis & - & TT & Ding. C et al. [127] \\
\hline miR-146b-5p & tissue & Up & CCDC6 & $\begin{array}{l}\text { promoted proliferation, migration, invasion, and cell } \\
\text { cycle progression of PTC cells }\end{array}$ & - & $\mathrm{Dg}, \mathrm{TT}$ & Jia. M et al. [128] \\
\hline $\operatorname{miR}-145$ & tissue & Down & ZEB2 & $\begin{array}{l}\text { inhibited the migration, invasion, and tumorigenesis of } \\
\text { PTC cells }\end{array}$ & circ_NUP214 & TT & Li. X et al. [129] \\
\hline $\operatorname{miR}-520 c-3 p$ & tissue & Down & S100A4 & inhibited PTC cells proliferation & lncRNA-HOXA-AS2 & TT & Xia. F et al. [130] \\
\hline miR-15a-5p & tissue & Down & - & inhibited PTC cells growth & lncRNA-HOXA-AS2 & TT & Jiang. L et al. [131] \\
\hline miR-146b-3p & tissue & Up & NF2 & increased PTC cell migration and invasion & - & TT & Yu. C et al. [132] \\
\hline miR-22a-3p & tissue & Up & CBL & promoted PTC cell proliferation and invasion & circ_ITCH & TT & Wang. M et al. [133] \\
\hline miR-21 & cell culture & - & PTEN & matrine- induced apoptosis and G1 cell cycle arrest & - & TT & Zhao. L et al. [134] \\
\hline $\mathrm{miR}-204$ & tissue & Down & BRD4 & inhibited of PTC cell proliferation & lncRNA-UCA1 & TT & Li. D et al. [135] \\
\hline $\operatorname{miR}-4429$ & tissue & Down & $\mathrm{Bcl}-2$ & $\begin{array}{l}\text { suppressed PTC cell proliferation, promoted apoptosis, } \\
\text { and induced cell cycle arrest in G2/M phase }\end{array}$ & lncRNA-LINC00313 & TT & Wu. JW et al. [136] \\
\hline $\operatorname{miR}-222$ & tissue & Up * & PPP2R2A & promoted PTC cell migration and invasion & - & $\mathrm{Dg}, \mathrm{TT}$ & Huang. Y et al. [137] \\
\hline $\operatorname{miR}-21-5 p$ & tissue & Down & $\mathrm{Bcl}-2$ & $\begin{array}{l}\text { inhibited TPC cell } \\
\text { proliferation and invasion }\end{array}$ & lncRNA-BISPR & $\mathrm{Dg}, \mathrm{TT}$ & Zhang. H et al. [138] \\
\hline $\mathrm{miR}-30 \mathrm{a}$ & tissue & Down & IGF1R & $\begin{array}{l}\text { inhibited PTC cell proliferation, cycle progression, } \\
\text { invasion, migration }\end{array}$ & lncRNA-PVT1 & TT & Feng. K et al. [139] \\
\hline miR-129-5p & tissue & Down & KLK7 & $\begin{array}{l}\text { inhibited proliferation, cell survival, invasion, } \\
\text { and migration }\end{array}$ & $\operatorname{lncRNA-NEAT1}$ & TT & Zhang. $\mathrm{H}$ et al. [140] \\
\hline $\begin{array}{l}\text { Ex-miR-146b-5p, } \\
\text { Ex-miR-222-5p }\end{array}$ & blood & Down & - & $\begin{array}{l}\text { enhanced the migration and invasion activity of } \\
\text { PTC cells }\end{array}$ & - & $\mathrm{Pg}$ & Jiang. K et al. [141] \\
\hline miR-539 & tissue & Down & SLPI & inhibited PTC cell EMT and tumor growth & - & TT & Xu. CB et al. [142] \\
\hline
\end{tabular}


Table 1. Cont.

\begin{tabular}{|c|c|c|c|c|c|c|c|}
\hline miRNA & $\begin{array}{l}\text { Sample } \\
\text { Sources }\end{array}$ & $\begin{array}{l}\text { Up/Down- } \\
\text { Regulated }\end{array}$ & $\begin{array}{l}\text { Targeted } \\
\text { Gene }\end{array}$ & miRNA Effect on PTC Cells & $\begin{array}{l}\text { Sponging/ } \\
\text { Sequestering }\end{array}$ & $\begin{array}{l}\text { Potential } \\
\text { Utility }\end{array}$ & References \\
\hline $\operatorname{miR}-24-3 p$ & tissue & Up & p27kip1 & $\begin{array}{l}\text { regulated PTC cell proliferation, apoptosis migration } \\
\text { and invasion }\end{array}$ & ncRNA-MIR22HG & $\mathrm{TT}$ & Chen. ZB et al. [143] \\
\hline $\mathrm{miR}-26 \mathrm{a}$ & cell culture & Down & ARPP19 & promoted proliferation of PTC cells & - & TT & Gong. Y et al. [144] \\
\hline Ex-miR-98-5p & blood & Down & HMGA2 & promoted PTC cell growth, inhibited apoptosis & - & $\mathrm{Dg}, \mathrm{Pg}$ & Qiu. K et al. [145] \\
\hline miR-296-5p & tissue & Down & PLK1 & $\begin{array}{l}\text { suppressed cell proliferation, inhibited cell clone } \\
\text { formation, arrested the cell cycle in G2/M phase, } \\
\text { and induced apoptosis }\end{array}$ & - & $\mathrm{TT}$ & Zhou. SL et al. [146] \\
\hline $\operatorname{miR}-451 a$ & cell culture & Down * & PSMB8 & $\begin{array}{l}\text { inhibited proliferation, EMT and induced apoptosis of } \\
\text { PTC cells }\end{array}$ & - & $\mathrm{TT}$ & Fan. X et al. [147] \\
\hline $\mathrm{miR}-630$ & tissue & Down & $\begin{array}{l}\text { JAK2/ } \\
\text { STAT3 }\end{array}$ & suppressed migration and invasion of PTC cells & - & $\mathrm{TT}$ & Pan. XM et al. [148] \\
\hline
\end{tabular}

TT—-therapeutic target, Dg-Diagnosis, Pg—Prognostic, Pr—Prevention, * The feature discovered in another study than the one cited. 


\subsection{Up- and Downregulated microRNAs in Papillary Thyroid Cancer}

Out of 139 microRNAs, 106 are downregulated and 33 are upregulated (Table 1). This means that more than a quarter of the described microRNAs have an oncogenic role (oncomiR's) and the rest of them have a tumor-suppressive role. The dysregulation of microRNA is an important event during the development of papillary thyroid carcinoma. Overexpression of certain microRNA can result in the tumor suppressor genes repression. Down-regulation of specific microRNA can lead to increased expression of oncogenes. Overexpression and downregulation induce malignant effects on cell cycle progression, proliferation, migration, and apoptosis, leading to tumor growth and progression in PTC and other types of malignancies [1].

\subsection{One Gene Can Be Targeted by Several microRNAs}

Analyzing, individually, in each study, the interaction between microRNAs and the genes targeted by them, we noticed that the same gene can be targeted by different microRNAs. For example, HMGB1 has been reported to play an important role in promoting both cell survival and death by regulating multiple signaling pathways, including proliferation, autophagy, inflammation, invasion, and metastasis. The study by Ding. $C$ et al. [127] indicates that microRNA-let-7e downregulates HMGB1 expression by directly targeting the HMGB1 3'-UTR, downregulated HMGB1 inhibits PTC cell proliferation and metastasis [127]. MicroRNA-1179 interacted with the 3' UTR of HMGB1 and suppressed HMGB1 expression at the post-transcriptional level and indicates that the microRNA-1179/MHGB1 pathway plays a tumor suppressor role in PTC [97]. The same gene-HMGB1 is involved in ANRIL/HMGB1/ microRNA-320a pathway. Propofol-mediated ANRIL downregulation competed with HMGB1 to bind microRNA-320a, thus inhibiting PTC cell malignant behaviors [42].

A study by Chen et al. [18] has shown that enforced expression of microRNA-202-3p inhibited WNT signaling by downregulating $\beta$-catenin expression in PTC. Again, the same gene is regulated by microRNA-3619-3p to promote cell migration and invasion in PTC [102]. WNT1 has been shown to promote cancer progression because it triggers cell proliferation and metastasis, microRNA-329 inhibits papillary thyroid cancer progression via direct targeting WNT1 [90]. WNT5a, an important signaling molecule in the non-canonical Wnt family, has been involved in nearly all parts of the non-canonical Wnt pathway. The invasion and metastasis of PTC cells were inhibited by microRNA-26a- $5 p$ via Wnt5a [66].

B-cell lymphoma-2 (Bcl-2), an oncogene expressed in most thyroid carcinomas, is also found to be a target of several different microRNAs. MicroRNA-21-5p suppressed Bcl-2 expression [138], silencing LINC00313 led to down-regulation of anti-apoptotic Bcl-2 proteins [136]. Overexpression of miR microARN-203 may serve a role in PTC tumor cells by downregulating Bcl-2 expression [91].

One more targeted gene by multiple microRNAs in PTC is AKT, the human homolog of the viral oncogene v-Akt is related to protein kinases A (PKA) and C (PKC) in humans. The pathway that involves AKT inactivates several proapoptotic factors, AKT also activates transcription factors which promote anti-apoptotic genes. Overexpression of microRNA-15a inhibited the activation of the AKT pathway, which inhibited cell proliferation and promoted the process of apoptosis [39]. Upregulated microRNA-203 suppresses epithelial-mesenchymal transition (EMT), invasion, proliferation, and migration as well as induces apoptosis of PTC cells via downregulated AKT3 [101]. IncRNA n384546 could regulate the expression of AKT3 by sponging microRNA-145-5p [119]. IncRNA HOTTIP modulated Akt1 expression by regulating microRNA-637 in PTC cell lines [103].

Another example is the Sphingosine kinase (SPHK), an enzyme, catalyzing the formation of the prosurvival second messenger sphingosine-1-phosphate (S1P) from the pro-apoptotic lipid sphingosine. High SPHK expression is correlated with a significant decrease in survival rate in patients with several forms of cancer, including PTC. LncRNA LINC00460 promoted PTC progression via modulating SphK2 through sponging microRNA-613 in PTC [26]. lncRNA LINC00520 accelerates the progression of papillary thyroid carcinoma by serving as a competing endogenous RNA of microRNA-577 to 
increase SphK2 expression [72]. MicroRNA-128 targets SPHK1 to induce apoptosis and reduce cell proliferation, migration in thyroid cancer cell lines, and inhibits tumor growth [14].

PTEN (phosphatase with tensin homology), an upstream negative regulatory molecule of the PI3K/AKT pathway, is the direct target gene of microRNA-106 [116] and microRNA-21 [134]. MicroRNA-625-3p [24] and microRNA-564 [67] directly target the same gene, AEG-1 (astrocyte elevated gene 1), an important regulator of PTC genesis and development. Yes-associated protein 1 (YAP1) was identified as a target gene of microRNA -205 [44] and microRNA-200a-3p [89]. Both microRNA-361-5p [46] and microRNA-26a [92] target ROCK1 (Rho-associated coiled-coil kinase 1), which was closely associated with poor PTC prognosis [46]. Zinc Finger E-Box Binding Homeobox 1 (ZEB1) a gene that plays vital roles in the metastasis of cancer, is inhibited by microRNA-451a [80] and a direct target of microRNA-429 [31].

From the same families of genes discovered to be the target of several microRNAs we mention CXCL-12/16 [16,86], CCNG-1/2 [17,100], IRS-1/2 [19,107], FGF-2/FR [28,112], CCDC-6/67 [52,128], FOX-O1/E1/M1 [27,55,76], ITGA-3/6 [55,61], SL-1A5/25A1 [56,118], MAP-2K4/K1/4K3 [71,78,120], and SOX 11/12/2 [84,95,117].

\subsection{One MicroRNA Can Target Several mRNAs/Genes}

One microRNA does not target only one but several mRNA/genes, as it was stated before. In our study, we found several microRNAs with multiple genes targeted. For instance, microRNA-146b-5p, downregulated CCDC6 expression by binding to its $3^{\prime}$-UTR in the study by Jia et al. [128] and promoted the expression of MALAT1 by negatively regulating DNMT3A in the study by Peng et al. [63]. The same microRNA-146b, but with the $3 p$ strand located in the reverse position compared to the $5 p$ strand which is present in the forward $\left(5^{\prime}-3^{\prime}\right)$ position, meaning microRNA-146b-3p, is targeting directly NF2 [132]. From the same family, microRNA-146a targets GABPA [58], and microRNA-146 targets KIT [114]. MicroRNA-199a-5p inhibited cell migration, invasion, and EMT by targeting SNAI in PTC [60] but also attenuated cell proliferation, induced apoptosis, and arrested cells in the G0/G1 phase through regulating the expression of SLC1A5 [118]. From the same family, microRNA-199b-5p suppressed PTC cell aggressiveness by targeting STON2 [65]. MicroRNA-101 suppresses the proliferation, apoptosis resistance, invasion, and migration of PTC cells by directly targeting CXCL12 [16]. MicroRNA-101-3p deficiency enhanced the expression level of FN1, which therefore promoted the RAI (radioactive iodine)-resistance of PTC [49]. Another example is microRNA-150 which serves a key function in suppressing the malignant growth and aggressive behavior of PTC cells through the downregulation of MUC4 [22]. Overexpression of microRNA-150-5p regulated cell proliferation, metastasis, and apoptosis by regulating BRAFV600E [94]. Both the IGF1R [139] and E2F7 [32] genes are targeted directly by the microRNA-30a. MicroRNA-203 inhibits proliferation and motility, and induces apoptosis of PTC cells via regulation of the expression of Bcl-2 [91], and suppresses EMT, invasion, proliferation, and migration of PTC cells via downregulated AKT3 [101]. Five more genes are found to be the target of the same microRNA in four different studies. VHL [104], Bcl-2 [138], PTEN [134], TGFBI [122], and COL4A1 [122] are all targeted genes by microRNA-21. There are still more examples of the same microRNA's but with the $3 p$ strand located in the reverse position compared to $5 p$ strand which is present in the forward $\left(5^{\prime}-3^{\prime}\right)$ position, that target different genes: [52,108], [119,129], [29,140], [37,73], [39,131], [45,135], [48,120], [50,68], [66,92], and [57,117].

\section{Discussion}

Each microRNA can regulate hundreds of messenger RNAs (mRNAs), while various microRNA can control the same mRNA. Additionally, many microRNAs regulate and are regulated by other species of non-coding RNAs, such as circular RNAs (circRNAs) and long non-coding RNAs (lncRNAs). For this reason, it is extremely difficult to predict, study, and analyze the precise role of a single microRNA involved in human cancer, considering the complexity of its connections. Focusing on a single microRNA molecule represents a limited approach. Additional information could come 
from network analysis, which has become a common tool in the biological field to better understand molecular interactions [1].

Most studies assess the level of expression of the microRNA in question, show the actions of its overexpression/silencing on cell lines, find the gene targeted by the microRNA, and how the metabolic pathway microRNA / target gene works. Although complex information is presented, at the end of the discussion chapter we find the same dry phrase "microRNA-X could be a potential therapeutic/diagnostic/prognostic target for PTC treatment". Despite this, there are several articles with a different study design that offer something more than "could be". One of them is the study of Zhao. L et al. [134] which finds Matrine, a traditional Chinese medicine, as an alternative drug for PTC treatment. Treatment with matrine at the concentrations of 1, 2, 5, 10, and $20 \mathrm{mg} / \mathrm{ml}$ inhibited TPC 1 cell proliferation by up to $95.8 \%$ (for $20 \mathrm{mg} / \mathrm{ml}$ matrine). Matrine induced apoptosis and G1 cell cycle arrest through downregulating microRNA-21 to affect the PTEN/Akt signaling in TPC 1 human thyroid cancer cells. Liu. F et al. [121] discovered that microRNA-206 contributed to euthyrox resistance in PTC cells through blockage p38 and JNK signaling pathway by targeting MAP4K3. Another study by Liu et al. [49], found the promoting gene and the signaling pathway regulating RAI-resistance in PTC. The results attested that NEAT1 was upregulated in RAI-resistant PTC accompanied microRNA-101-3p inhibition, FN1 overexpression, and PI3K/AKT signaling pathway abnormal activation. Fang. T et al. [23] discovered that Shenmai injection (SMI), a traditional Chinese formula mainly made up of Red Ginseng and Radix Ophiopogonis. SMI inhibits the differentiation of CD4 + T cells into Treg cells via the microRNA-103/GPER1 axis, which improves the immunological function of PTC patients with postoperative 131-Iodine ablation. Although few, these studies differ in the classical approach to the use of microRNAs in papillary thyroid carcinomas and should be recognized as at least promising.

Even if in the world of publications microRNA is a hot topic, when we talk about PTC, most international guidelines regarding thyroid cancer management, do not even mention microRNA. Here we refer to the NCCN 2018 [149], ETA 2019 [7], and ESMO 2019 [11] guidelines. The exception is the ATA 2015 guideline, which, although published several years before the above-listed guidelines, mentions microRNA as an additional diagnostic molecular marker strategy under development. microRNA markers have shown initial diagnostic utility in FNA samples with indeterminate cytological diagnoses, but they have not been thoroughly validated. It is also mentioned about microRNA, also in this guide, in the chapter "Directions for future research", as possible progress in identifying markers of thyroid cancer. To result in a significantly improved accuracy of cancer detection in thyroid nodules as compared to the currently available clinical tests [8].

Hence, which are the most challenging parts in PTC management where we could use microRNA? After the clinical and ultrasound evaluation of a thyroid nodule, if malignancy criteria are present, a fine needle biopsy is performed for cytological examination. Some results of the cytological examination can be inconclusive. In such cases, there is a need to assess molecular markers to make a presurgical differentiation of benign and malign lesions. MicroRNAs are one of the novel classes of molecular markers that are being used to improve the diagnosis of thyroid cancer. Several studies have shown that a microRNA-based signature in FNABs can be used to discriminate benign from malignant thyroid nodules. MicroRNA profiling of thyroid cancers can also provide prognostic information useful for defining optimal management strategies. Expression levels of certain microRNA in thyroid tumor tissues are associated with clinicopathological characteristics, such as tumor size, multifocality, capsular invasion, extrathyroidal extension, and both lymph node and distant metastases [150]. Treatment options have been proposed and implemented based on the results obtained from research conducted on epigenetic alterations. Therefore, the development of new therapeutic strategies based on targeting epigenetic changes to restore the expression of tumor suppressor microRNAs or to blunt overexpressed oncogenic microRNAs may provide a new landscape for the treatment of aggressive PTC [151]. 
Although PTMC generally has an excellent prognosis, the long-term rate of recurrence of PTMC has been reported to be as high as 10\% [9]. Currently, there are no reliable clinical features including molecular markers, that can differentiate PTMC in patients who develop progressive disease from indolent PTMC. Even so, searching the PubMed database, regarding microRNA signatures in PTMC, there is only one study by Zhang et al. which combines serum microRNA with ultrasound profile as predictive biomarkers of diagnosis and prognosis for PTMC. In this study, microRNAs were found to be significantly associated with a poor prognosis of patients with PTMC and could be used as prognostic molecular markers or patients with PTMC before and after surgery. These results suggest that circulating microRNAs may be useful as non-invasive molecular biomarkers of diagnosis and prognosis for PTMC [9], selecting those cases that need aggressive therapies, despite the histology of PTMC. Given the need for more studies in this field, this topic could be a research idea for the future, in the era of personalized medicine.

\section{Conclusions}

Research regarding microRNAs in PTC is undergoing a tremendous shift, suggesting rapid maturation of this field. In this review, we tried to represent as briefly as possible the interactions of microRNAs with target proteins. We also showed microRNAs regulation mode and its effect on PTC cells. Our results showed that a gene can target multiple microRNAs simultaneously, and vice versa. All this information can be used to find the most effective therapeutic targets/biomarkers in PTC. For future research, we indicated a possible niche, namely microRNA signatures in PTMC.

Author Contributions: Conceptualization, L.H., A.P., D.P. Data curation, L.H., A.-C.H., K.G.; Formal analysis, E.-A.B., A.P.; Investigation, L.H., D.P., P.-A.Ș.; Methodology, A.P., A.-C.H., D.P.; Supervision, D.P. All authors have read and agreed to the published version of the manuscript.

Funding: This research received no external funding.

Conflicts of Interest: The authors declare no conflict of interest.

\section{References}

1. Dragomir, M.; Mafra, A.C.P. Using microRNA Networks to Understand Cancer. Int. J. Mol. Sci. 2018, 19, 1871. [CrossRef] [PubMed]

2. Zembska, A.; Jawiarczyk-Przybyłowska, A. MicroRNA Expression in the Progression and Aggressiveness of Papillary Thyroid Carcinoma. Anticancer Res. 2019, 39, 33-40. [CrossRef] [PubMed]

3. Farazi, T.; Hoell, J. MicroRNAs in human cancer. Adv. Exp. Med. Biol. 2013, 774, 1-20. [PubMed]

4. Zhang, Y.; $\mathrm{Xu}, \mathrm{D}$. Dynamic monitoring of circulating microRNAs as a predictive biomarker for the diagnosis and recurrence of papillary thyroid carcinoma. Oncol. Lett. 2017, 13, 4252-4266. [CrossRef]

5. Santiago, K.; Chen Wongworawat, Y. Differential MicroRNA-Signatures in Thyroid Cancer Subtypes. J. Oncol. 2020, 2020, 2052396. [CrossRef]

6. Piciu, D.; Irimie, A. Investigation of thyroid carcinoma over 40 years, using the database of the Ion Chiricuta Institute of Oncology Cluj-Napoca. J. BUON 2014, 19, 524-529.

7. Fugazzola, L.; Elisei, R. 2019 European Thyroid Association Guidelines for the Treatment and Follow-Up of Advanced Radioiodine-Refractory Thyroid Cancer. Eur. Thyroid J. 2019, 8, 227-245. [CrossRef]

8. Haugen, B.R.; Alexander, E.K. 2015 American Thyroid Association Management Guidelines for Adult Patients with Thyroid Nodules and Differentiated Thyroid Cancer: The American Thyroid Association Guidelines Task Force on Thyroid Nodules and Differentiated Thyroid Cancer. Thyroid 2016, 26, 1-133. [CrossRef]

9. Zhang, Y.; Pan, J. Combination of serum microRNAs and ultrasound profile as predictive biomarkers of diagnosis and prognosis for papillary thyroid microcarcinoma. Oncol. Rep. 2018, 40, 3611-3624. [CrossRef]

10. Piciu, D.; Irimie, A. Diagnostic and treatment guidelines in thyroid carcinoma. American and Europeanconsensus, adapted to Romania. Acta. Endodontol. 2007, 3, 103-115.

11. Filetti, S.; Durante, C. ESMO Guidelines Committee. Thyroid cancer: ESMO Clinical Practice Guidelines for diagnosis, treatment and follow-upt. Ann. Oncol. 2019, 30, 1856-1883. [CrossRef] [PubMed] 
12. Bi, C.L.; Zhang, Y.Q. MicroRNA-520a-3p suppresses epithelial-mesenchymal transition, invasion, and migration of papillary thyroid carcinoma cells via the JAK1-mediated JAK/STAT signaling pathway. J. Cell Physiol. 2019, 234, 4054-4067. [CrossRef] [PubMed]

13. Cai, X.; Zhao, Z. Circular RNA circBACH2 plays a role in papillary thyroid carcinoma by sponging miR-139-5p and regulating LMO4 expression. Cell Death Dis. 2019, 10, 184. [CrossRef] [PubMed]

14. Cao, X.Z.; Bin, H. MiR-128 suppresses the growth of thyroid carcinoma by negatively regulating SPHK1. Biomed Pharmacother 2019, 109, 1960-1966. [CrossRef]

15. Chen, F.; Yin, S. IncRNA DGCR5 acts as a tumor suppressor in papillary thyroid carcinoma via sequestering miR-2861. Exp. Ther. Med. 2019, 17, 895-900. [CrossRef]

16. Chen, F.; Yang, D. MicroRNA-101 Targets CXCL12-Mediated Akt and Snail Signaling Pathways to Inhibit Cellular Proliferation and Invasion in Papillary Thyroid Carcinoma. Oncol. Res. 2019, 27, 691-701. [CrossRef]

17. Chen, N.; Yin, D. LncRNA GAS8-AS1 suppresses papillary thyroid carcinoma cell growth through the miR-135b-5p/CCND2 axis. Biosci. Rep. 2019, 39, BSR20181440. [CrossRef]

18. Chen, J.; Yin, J. MiR-202-3p functions as a tumor suppressor and reduces cell migration and invasion in papillary thyroid carcinoma. Eur. Rev. Med. Pharmacol. Sci. 2019, 23, 1145-1150.

19. Chen, Y.; Hao, S.A. MicroRNA-1271 inhibits the progression of papillary thyroid carcinoma by targeting IRS1 and inactivating AKT pathway. Eur. Rev. Med. Pharmacol. Sci. 2019, 23, 7989-7999.

20. Cui, Z.; Luo, Z. Long non-coding RNA TTN-AS1 facilitates tumorigenesis of papillary thyroid cancer through modulating the miR-153-3p/ZNRF2 axis. J. Gene Med. 2019, 21, e3083. [CrossRef]

21. Du, Y.; Zhu, J. MiR-548c-3p suppressed the progression of papillary thyroid carcinoma via inhibition of the HIF1 $\alpha$-mediated VEGF signaling pathway. Eur. Rev. Med. Pharmacol. Sci. 2019, 23, 6570-6578. [PubMed]

22. Fa, Z.; Min, Z. MicroRNA-150 suppresses the growth and malignant behavior of papillary thyroid carcinoma cells via downregulation of MUC4. Exp. Ther. Med. 2018, 16, 45-52. [CrossRef] [PubMed]

23. Fang, T.; Li, J. Shenmai injection improves the postoperative immune function of papillary thyroid carcinoma patients by inhibiting differentiation into Treg cells via miR-103/GPER1 axis. Drug Dev. Res. 2018, 79, 324-331. [CrossRef] [PubMed]

24. Fang, L.; Kong, D. MicroRNA-625-3p promotes the proliferation, migration and invasion of thyroid cancer cells by up-regulating astrocyte elevated gene 1. Biomed Pharmacother 2018, 102, 203-211. [CrossRef]

25. Fang, M.; Huang, W. MiR-141-3p Suppresses Tumor Growth and Metastasis in Papillary Thyroid Cancer via Targeting Yin Yang 1. Anat Rec. (Hoboken) 2019, 302, 258-268. [CrossRef]

26. Feng, L.; Yang, B. Long noncoding RNA LINC00460 promotes carcinogenesis via sponging miR-613 in papillary thyroid carcinoma. J. Cell Physiol. 2019, 234, 11431-11439. [CrossRef]

27. Feng, Z.; Chen, R. Long non-coding RNA ASMTL-AS1 inhibits tumor growth and glycolysis by regulating the miR-93-3p/miR-660/FOXO1 axis in papillary thyroid carcinoma. Life Sci. 2020, 244, 117298. [CrossRef]

28. Fu, Y.T.; Zheng, H.B. MicroRNA-1266 suppresses papillary thyroid carcinoma cell metastasis and growth via targeting FGFR2. Eur. Rev. Med. Pharmacol. Sci. 2018, 22, 3430-3438.

29. Gao, X.; Chen, Z. MiR-129 regulates growth and invasion by targeting MAL2 in papillary thyroid carcinoma. Biomed Pharmacother 2018, 105, 1072-1078. [CrossRef]

30. Gao, X.B.; Chen, C.L. MicroRNA-791 is an independent prognostic factor of papillary thyroid carcinoma and inhibits the proliferation of PTC cells. Eur. Rev. Med. Pharmacol. Sci. 2018, 22, 5562-5568.

31. Gao, H.; Sun, X. Long noncoding RNA SNHG22 increases ZEB1 expression via competitive binding with microRNA-429 to promote the malignant development of papillary thyroid cancer. Cell Cycle 2020, 19, 1186-1199. [CrossRef]

32. Guo, H.; Zhang, L. MicroRNA-30a suppresses papillary thyroid cancer cell proliferation, migration and invasion by directly targeting E2F7. Exp. Ther. Med. 2019, 18, 209-215. [CrossRef] [PubMed]

33. Guo, F.; Hou, X. MicroRNA-9-5p functions as a tumor suppressor in papillary thyroid cancer via targeting BRAF. Oncol. Lett. 2018, 16, 6815-6821. [CrossRef] [PubMed]

34. Han, J.; Zhang, M. miR-215 suppresses papillary thyroid cancer proliferation, migration, and invasion through the AKT/GSK-3 $\beta /$ Snail signaling by targeting ARFGEF1. Cell Death Dis. 2019, 10, 195. [CrossRef] [PubMed]

35. He, T.; Wang, H. Altered expression of DLG1-AS1 distinguished papillary thyroid carcinoma from benign thyroid nodules. BMC Endocr. Disord. 2019, 19, 122. [CrossRef] 
36. Hu, Z.; Zhao, P. Hsa_circ_0011290 regulates proliferation, apoptosis and glycolytic phenotype in papillary thyroid cancer via miR-1252/FSTL1 signal pathway. Arch. Biochem. Biophys. 2020,685, 108353. [CrossRef] [PubMed]

37. Jiao, X.; Ye, J. KIAA1199, a Target of MicoRNA-486-5p, Promotes Papillary Thyroid Cancer Invasion by Influencing Epithelial-Mesenchymal Transition (EMT). Med. Sci. Monit. 2019, 25, 6788-6796. [CrossRef] [PubMed]

38. Jin, X.; Wang, Z. Upregulated hsa_circ_0004458 Contributes to Progression of Papillary Thyroid Carcinoma by Inhibition of miR-885-5p and Activation of RAC1. Med. Sci. Monit. 2018, 24, 5488-5500. [CrossRef]

39. Jin, J.; Zhang, J. miRNA-15a regulates the proliferation and apoptosis of papillary thyroid carcinoma via regulating AKT pathway. Onco. Targets. Ther. 2019, 12, 6217-6226. [CrossRef]

40. Kong, W.; Yang, L. MiR-381-3p inhibits proliferation, migration and invasion by targeting LRP6 in papillary thyroid carcinoma. Eur. Rev. Med. Pharmacol. Sci. 2018, 22, 3804-3811.

41. Li, G.; Kong, Q. LncRNA LINC00460 promotes the papillary thyroid cancer progression by regulating the LINC00460/miR-485-5p/Raf1 axis. Biol. Res. 2019, 52, 61. [CrossRef] [PubMed]

42. Li, M.; Qu, L. Propofol upregulates miR-320a and reduces HMGB1 by downregulating ANRIL to inhibit PTC cell malignant behaviors. Pathol. Res. Pract. 2020, 216, 152856. [CrossRef] [PubMed]

43. Li, P.; Dong, M. Downregulation of TSPAN13 by miR-369-3p inhibits cell proliferation in papillary thyroid cancer (PTC). Bosn. J. Basic. Med. Sci. 2019, 19, 146-154. [CrossRef]

44. Li, D.; Wang, Q. miR 205 targets YAP1 and inhibits proliferation and invasion in thyroid cancer cells. Mol. Med. Rep. 2018, 18, 1674-1681. [CrossRef]

45. Li, X.; Zhong, W. Silencing of lncRNA LINC00514 inhibits the malignant behaviors of papillary thyroid cancer through miR-204-3p/CDC23 axis. Biochem. Biophys. Res. Commun. 2019, 508, 1145-1148. [CrossRef] [PubMed]

46. Li, R.; Dong, B. MicroRNA-361-5p inhibits papillary thyroid carcinoma progression by targeting ROCK1. Biomed. Pharmacother 2018, 102, 988-995. [CrossRef] [PubMed]

47. Li, R.; Teng, X. MiR-4500 Regulates PLXNC1 and Inhibits Papillary Thyroid Cancer Progression. Horm. Cancer 2019, 10, 150-160. [CrossRef] [PubMed]

48. Liang, M.; Jia, J. LncRNA MCM3AP-AS1 promotes proliferation and invasion through regulating miR-211-5p/SPARC axis in papillary thyroid cancer. Endocrine 2019, 65, 318-326. [CrossRef]

49. Liu, C.; Feng, Z. Downregulation of NEAT1 reverses the radioactive iodine resistance of papillary thyroid carcinoma cell via miR-101-3p/FN1/PI3K-AKT signaling pathway. Cell Cycle 2019, 18, 167-203. [CrossRef]

50. Liu, F.; Lou, K. miR-214 regulates papillary thyroid carcinoma cell proliferation and metastasis by targeting PSMD10. Int. J. Mol. Med. 2018, 42, 3027-3036. [CrossRef]

51. Liu, H.; Guo, J. MicroRNA 744 suppresses cell proliferation and invasion of papillary thyroid cancer by directly targeting NOB1. Mol. Med. Rep. 2019, 19, 1903-1910. [CrossRef] [PubMed]

52. Liu, Z.M.; Wu, Z.Y. MiR-96-5p promotes the proliferation, invasion and metastasis of papillary thyroid carcinoma through down-regulating CCDC67. Eur. Rev. Med. Pharmacol. Sci. 2019, 23, 3421-3430. [PubMed]

53. Liu, Z.; Zhang, J. MicroRNA-4728 mediated regulation of MAPK oncogenic signaling in papillary thyroid carcinoma. Saudi J. Biol. Sci. 2018, 25, 986-990. [CrossRef]

54. Liu, Y.; Li, L. Downregulation of MiR-431 expression associated with lymph node metastasis and promotes cell invasion in papillary thyroid carcinoma. Cancer Biomark 2018, 22, 727-732. [CrossRef]

55. Liu, H.; Chen, X. MicroRNA-524-5p suppresses the progression of papillary thyroid carcinoma cells via targeting on FOXE1 and ITGA3 in cell autophagy and cycling pathways. J. Cell Physiol. 2019, 234, 18382-18391. [CrossRef] [PubMed]

56. Liu, S.; Zhang, D. Long non-coding RNA BRM promotes proliferation and invasion of papillary thyroid carcinoma by regulating the microRNA-331-3p/SLC25A1 axis. Oncol. Lett. 2020, 19, 3071-3078. [CrossRef]

57. Luo, L.; Xia, L. miR-335-5p targeting ICAM-1 inhibits invasion and metastasis of thyroid cancer cells. Biomed. Pharmacother 2018, 106, 983-990. [CrossRef]

58. Long, M.; Zhu, Y. Lysine-Specific Demethylase 1 Affects the Progression of Papillary Thyroid Carcinoma via HIF1 $\alpha$ and microRNA-146a. J. Clin. Endocrinol. Metab. 2020, 105, dgaa182. [CrossRef]

59. Ma, Y.; Sun, Y. miR-29a-3p inhibits growth, proliferation, and invasion of papillary thyroid carcinoma by suppressing NF-kB signaling via direct targeting of OTUB2. Cancer Manag. Res. 2018, 11, 13-23. [CrossRef] 
60. Ma, S.; Jia, W. miR-199a-5p inhibits the progression of papillary thyroid carcinoma by targeting SNAI1. Biochem. Biophys. Res. Commun. 2018, 497, 181-186. [CrossRef]

61. Pan, Y.; Zhu, X. MicroRNA-363-3p suppresses anoikis resistance in human papillary thyroid carcinoma via targeting integrin alpha 6. Acta Biochim. Biophys. Sin. (Shanghai) 2019, 51, 807-813. [CrossRef] [PubMed]

62. Pan, Y.; Xu, T. Upregulated circular RNA circ_0025033 promotes papillary thyroid cancer cell proliferation and invasion via sponging miR-1231 and miR-1304. Biochem. Biophys. Res. Commun. 2019, 510, 334-338. [CrossRef]

63. Peng, Y.; Fang, X. MiR-146b-5p Regulates the Expression of Long Noncoding RNA MALAT1 and Its Effect on the Invasion and Proliferation of Papillary Thyroid Cancer. Cancer Biother Radiopharm 2020. [CrossRef] [PubMed]

64. Pu, Y.; Xiang, J. KDM5B-mediated microRNA-448 up-regulation restrains papillary thyroid cancer cell progression and slows down tumor growth via TGIF1 repression. Life Sci. 2020, 250, 117519. [CrossRef] [PubMed]

65. Ren, L.; Xu, Y. miR-199b-5p-Stonin 2 axis regulates metastases and epithelial-to-mesenchymal transition of papillary thyroid carcinoma. IUBMB Life 2019, 71, 28-40. [CrossRef] [PubMed]

66. Shi, D.; Wang, H. MicroRNA-26a-5p inhibits proliferation, invasion and metastasis by repressing the expression of Wnt5a in papillary thyroid carcinoma. Onco. Targets Ther. 2019, 12, 6605-6616. [CrossRef] [PubMed]

67. Song, Z.; Yang, H. microRNA-564 inhibits the aggressive phenotypes of papillary thyroid cancer by directly targeting astrocyte-elevated gene-1. Onco. Targets. Ther. 2019, 12, 4869-4881. [CrossRef]

68. Sui, G.; Zhang, B. The lncRNA SNHG3 accelerates papillary thyroid carcinoma progression via the miR-214-3p/PSMD10 axis. J. Cell Physiol. 2020, 235, 6615-6624. [CrossRef]

69. Sun, W.; Lan, X. MicroRNA-144 inhibits proliferation by targeting WW domain-containing transcription regulator protein 1 in papillary thyroid cancer. Oncol. Lett. 2018, 15, 1007-1013. [CrossRef]

70. Sun, W.; Lan, X. NEAT1_2 functions as a competing endogenous RNA to regulate ATAD2 expression by sponging microRNA-106b-5p in papillary thyroid cancer. Cell Death Dis. 2018, 9, 380. [CrossRef]

71. Sun, Y.; Zhang, L. microRNA-124-3p inhibits tumourigenesis by targeting mitogen-activated protein kinase 4 in papillary thyroid carcinoma. Cell Biochem. Funct. 2020. [CrossRef] [PubMed]

72. Sun, Y.; Shi, T. Long noncoding RNA LINC00520 accelerates progression of papillary thyroid carcinoma by serving as a competing endogenous RNA of microRNA-577 to increase Sphk2 expression. Cell Cycle 2020, 19, 787-800. [CrossRef] [PubMed]

73. Sun, Y.H.; Liu, Z.F. MicroRNA-486 inhibits cell proliferation, invasion and migration via down-regulating the TENM1 expressions and affecting ERK and Akt signaling pathways and epithelial-to-mesenchymal transition in papillary thyroid carcinoma. Eur. Rev. Med. Pharmacol. Sci. 2019, 23, 8429-8439.

74. Sun, Z.; Guo, X. Long non-coding RNA LINC00152 promotes cell growth and invasion of papillary thyroid carcinoma by regulating the miR-497/BDNF axis. J. Cell Physiol. 2019, 234, 1336-1345. [CrossRef] [PubMed]

75. Wang, D.; Guo, C. Serum miR-22 may be a biomarker for papillary thyroid cancer. Oncol. Lett. 2019, 17, 3355-3361. [CrossRef]

76. Wang, D.P.; Tang, X.Z. microRNA-599 promotes apoptosis and represses proliferation and epithelial-mesenchymal transition of papillary thyroid carcinoma cells via downregulation of Hey2-depentent Notch signaling pathway. J. Cell Physiol. 2020, 235, 2492-2505. [CrossRef]

77. Wang, G.; Wang, X. LINC01410/miR-3619-5p/FOXM1 Feedback Loop Regulates Papillary Thyroid Carcinoma Cell Proliferation and Apoptosis. Cancer Biother. Radiopharm. 2019, 34, 572-580. [CrossRef] [PubMed]

78. Wang, J.; Xiao, T. MicroRNA-675 directly targets MAPK1 to suppress the oncogenicity of papillary thyroid cancer and is sponged by long non-coding RNA RMRP. Onco. Targets Ther. 2019, 12, 7307-7321. [CrossRef]

79. Wang, L.J.; Cai, H.Q. miR-1258: A novel microRNA that controls TMPRSS4 expression is associated with malignant progression of papillary thyroid carcinoma. Endokrynol. Pol. 2020, 71, 146-152. [CrossRef]

80. Wang, Q.; Shang, J. MiR-451a restrains the growth and metastatic phenotypes of papillary thyroid carcinoma cells via inhibiting ZEB1. Biomed. Pharmacother 2020, 127, 109901. [CrossRef]

81. Wang, R.; Ma, Q. miR-622 suppresses tumor formation by directly targeting VEGFA in papillary thyroid carcinoma. Onco. Targets Ther. 2018, 11, 1501-1509. [PubMed]

82. Wang, R.; Zhao, L. Myocardial infarction associated transcript (MIAT) promotes papillary thyroid cancer progression via sponging miR-212. Biomed Pharmacother 2019, 118, 109298. [CrossRef] [PubMed] 
83. Wang, X.; Qi, M. miR-718 is involved in malignancy of papillary thyroid cancer through repression of PDPK1. Pathol. Res. Pract. 2018, 214, 1787-1793. [CrossRef]

84. Wang, Y.; Liu, B.G. MicroRNA-31 inhibits papillary thyroid carcinoma cell biological progression by directly targeting SOX11 and regulating epithelial-to-mesenchymal transition, ERK and Akt signaling pathways. Eur. Rev. Med. Pharmacol. Sci. 2019, 23, 5863-5873. [PubMed]

85. Wang, Y.; Wang, B. MicroRNA-384 Inhibits the Progression of Papillary Thyroid Cancer by Targeting PRKACB. Biomed Res. Int. 2020, 2020, 4983420. [CrossRef]

86. Wang, Z.; Liu, W. miR-873-5p Inhibits Cell Migration and Invasion of Papillary Thyroid Cancer via Regulation of CXCL16. Onco. Targets Ther. 2020, 13, 1037-1046. [CrossRef] [PubMed]

87. Wang, Z.L.; Wang, C. Upregulation of microRNA-143-3p induces apoptosis and suppresses proliferation, invasion, and migration of papillary thyroid carcinoma cells by targeting MSI2. Exp. Mol. Pathol. 2020, 112, 104342. [CrossRef]

88. Wei, H.; Pan, L. Circular RNA circZFR contributes to papillary thyroid cancer cell proliferation and invasion by sponging miR-1261 and facilitating C8orf4 expression. Biochem. Biophys. Res. Commun. 2018, 503, 56-61. [CrossRef]

89. Wu, D.M.; Wang, S. LncRNA SNHG15 acts as a ceRNA to regulate YAP1-Hippo signaling pathway by sponging miR-200a-3p in papillary thyroid carcinoma. Cell Death Dis. 2018, 9, 947. [CrossRef]

90. Wu, L.; Pei, F. miR-329 inhibits papillary thyroid cancer progression via direct targeting WNT1. Oncol. Lett. 2018, 16, 3561-3568. [CrossRef]

91. Wu, X.; Dai, L. Overexpression of microRNA-203 can downregulate survivin and function as a potential therapeutic target in papillary thyroid cancer. Oncol. Lett. 2020, 19, 61-68. [CrossRef]

92. Wu, Y.C.; Li, S.Y. MicroRNA-26a suppresses the malignant biological behaviors of papillary thyroid carcinoma by targeting ROCK1 and regulating PI3K/AKT signaling pathway. Eur. Rev. Med. Pharmacol. Sci. 2019, 23, 8940-8949.

93. Xiang, D.; Tian, B. miR-222 expression is correlated with the ATA risk stratifications in papillary thyroid carcinomas. Medicine (Baltimore) 2019, 98, e16050. [CrossRef]

94. Yan, R.; Yang, T. MicroRNA-150-5p affects cell proliferation, apoptosis, and EMT by regulation of the BRAFV600E mutation in papillary thyroid cancer cells. J. Cell Biochem. 2018, 119, 8763-8772. [CrossRef]

95. Yang, C.; Liu, Z. NR2F1-AS1 regulated miR-423-5p/SOX12 to promote proliferation and invasion of papillary thyroid carcinoma. J. Cell Biochem. 2020, 121, 2009-2018. [CrossRef]

96. Yao, X.G.; Tan, Q. Tissue microRNA-182 expression level and its potential prognostic value for papillary thyroid carcinoma. Int. J. Clin. Exp. Pathol. 2019, 12, 3128-3133. [PubMed]

97. Ye, M.; Hou, H. Circular RNA circFOXM1 Plays a Role in Papillary Thyroid Carcinoma by Sponging miR-1179 and Regulating HMGB1 Expression. Mol. Ther. Nucleic Acids 2020, 19, 741-750. [CrossRef] [PubMed]

98. Yi, T.; Zhou, X. MicroRNA-1270 modulates papillary thyroid cancer cell development by regulating SCAI. Biomed Pharmacother 2019, 109, 2357-2364. [CrossRef]

99. Yin, X.; Zhang, J. LncRNA HOXA11-AS accumulation-induced microRNA-761 downregulation regulates cell growth by targeting TRIM29 in papillary thyroid cancer. Am. J. Transl. Res. 2019, 11, 6826-6837.

100. Yin, J.J.; Cheng, X.Y. MicroRNA-23a inhibits the growth of papillary thyroid carcinoma via regulating cyclin G1. Eur. Rev. Med. Pharmacol. Sci. 2019, 23, 3431-3439.

101. You, A.; Fu, L. MicroRNA-203 restrains epithelial-mesenchymal transition, invasion and migration of papillary thyroid cancer by downregulating AKT3. Cell Cycle 2020, 19, 1105-1121. [CrossRef] [PubMed]

102. Yu, S.; Cao, S. miR-3619-3p promotes papillary thyroid carcinoma progression via Wnt/ $\beta$-catenin pathway. Ann. Transl. Med. 2019, 7, 643. [CrossRef]

103. Yuan, Q.; Liu, Y. LncRNA HOTTIP promotes papillary thyroid carcinoma cell proliferation, invasion and migration by regulating miR-637. Int. J. Biochem. Cell Biol. 2018, 98, 1-9. [CrossRef] [PubMed]

104. Zang, C.; Sun, J. miRNA-21 promotes cell proliferation and invasion via VHL/PI3K/AKT in papillary thyroid carcinoma. Hum. Cell 2019, 32, 428-436. [CrossRef]

105. Zang, C.S.; Huang, H.T. MiR-224-5p targets EGR2 to promote the development of papillary thyroid carcinoma. Eur. Rev. Med. Pharmacol. Sci. 2020, 24, 4890-4900.

106. Zhang, S.; Wang, Q. MicroRNA 509 targets PAX6 to inhibit cell proliferation and invasion in papillary thyroid carcinoma. Mol. Med. Rep. 2019, 19, 1403-1409. [CrossRef] [PubMed] 
107. Zhao, J.; Li, Z. MicroRNA 766 inhibits papillary thyroid cancer progression by directly targeting insulin receptor substrate 2 and regulating the PI3K/Akt pathway. Int. J. Oncol. 2019, 54, 315-325. [CrossRef] [PubMed]

108. Zhao, X.; Li, Y. MicroRNA-96-3p promotes metastasis of papillary thyroid cancer through targeting SDHB. Cancer Cell Int. 2019, 19, 287. [CrossRef]

109. Zhao, Y.; Zhao, L. Silencing of long noncoding RNA RP11-476D10.1 enhances apoptosis and autophagy while inhibiting proliferation of papillary thyroid carcinoma cells via microRNA-138-5p-dependent inhibition of LRRK2. J. Cell Physiol. 2019, 234, 20980-20991. [CrossRef]

110. Zhao, Z.; Yang, F. MicroRNA-409-3p suppresses cell proliferation and cell cycle progression by targeting cyclin D2 in papillary thyroid carcinoma. Oncol. Lett. 2018, 16, 5237-5242. [CrossRef]

111. Zhou, B.; Xu, J. miR-200b/c-RAP1B axis represses tumorigenesis and malignant progression of papillary thyroid carcinoma through inhibiting the NF-кB/Twist1 pathway. Exp. Cell Res. 2020, 387, 111785. [CrossRef]

112. Zhou, P.; Irving, A. Validation of MicroRNA-188-5p Inhibition Power on Tumor Cell Proliferation in Papillary Thyroid Carcinoma. Cell Transplant. 2020, 29, 963689720918300. [CrossRef]

113. Zhu, J.; Zhang, Q. MiR-506 suppresses papillary thyroid carcinoma cell proliferation and metastasis via targeting IL17RD. Eur. Rev. Med. Pharmacol. Sci. 2019, 23, 2856-2862. [PubMed]

114. Liao, B.; Liu, S. Long Noncoding RNA CTC Inhibits Proliferation and Invasion by Targeting miR-146 to Regulate KIT in Papillary Thyroid Carcinoma. Sci. Rep. 2020, 10, 4616. [CrossRef]

115. Wu, G.; Zhou, W. Circular RNA Profiling Reveals Exosomal circ_0006156 as a Novel Biomarker in Papillary Thyroid Cancer. Mol. Ther. Nucleic Acids 2020, 19, 1134-1144. [CrossRef]

116. Yang, Z.; Li, G. Long non-coding RNA HULC exerts oncogenic activity on papillary thyroid cancer in vitro and in vivo. Artif Cells Nanomed. Biotechnol. 2020, 48, 326-335.

117. Li, Q.; Wang, X.J. SOX2-induced upregulation of lncRNA LINC01510 promotes papillary thyroid carcinoma progression by modulating miR-335/SHH and activating Hedgehog pathway. Biochem. Biophys. Res. Commun. 2019, 520, 277-283. [CrossRef]

118. Zhuang, X.; Tong, H. Long noncoding RNA ABHD11-AS1 functions as a competing endogenous RNA to regulate papillary thyroid cancer progression by miR-199a-5p/SLC1A5 axis. Cell Death Dis. 2019, 10, 620. [CrossRef]

119. Feng, J.; Zhou, Q. A novel lncRNA n384546 promotes thyroid papillary cancer progression and metastasis by acting as a competing endogenous RNA of miR-145-5p to regulate AKT3. Cell Death Dis. 2019, 10, 433. [CrossRef] [PubMed]

120. Wei, Z.L.; Gao, A.B. MicroRNA-221 promotes papillary thyroid carcinoma cell migration and invasion via targeting RECK and regulating epithelial-mesenchymal transition. Onco. Targets Ther. 2019, 12, 2323-2333. [CrossRef] [PubMed]

121. Liu, F.; Yin, R. Over-expression of miR-206 decreases the Euthyrox-resistance by targeting MAP4K3 in papillary thyroid carcinoma. Biomed. Pharmacother 2019, 114, 108605. [CrossRef] [PubMed]

122. Wu, F.; Li, F. Exosomes increased angiogenesis in papillary thyroid cancer microenvironment. Endocr. Relat. Cancer 2019, 26, 525-538. [CrossRef] [PubMed]

123. Ye, W.; Deng, X. Exosomal miRNA423-5p mediated oncogene activity in papillary thyroid carcinoma: A potential diagnostic and biological target for cancer therapy. Neoplasma 2019, 66, 516-523. [CrossRef] [PubMed]

124. Yan, D.G.; Liu, N. SP1-induced upregulation of long noncoding RNA LINC00313 contributes to papillary thyroid cancer progression via the miR-422a. Eur. Rev. Med. Pharmacol. Sci. 2019, 23, 1134-1144.

125. Wen, J.; Wang, H. STAT3-induced upregulation of lncRNA ABHD11-AS1 promotes tumour progression in papillary thyroid carcinoma by regulating miR-1301-3p/STAT3 axis and PI3K/AKT signalling pathway. Cell Prolif. 2019, 52, e12569. [CrossRef]

126. Huang, J.; Lin, H. Role of Lin28A/let-7a/c-Myc Pathway in Growth and Malignant Behavior of Papillary Thyroid Carcinoma. Med. Sci. Monit. 2018, 24, 8899-8909. [CrossRef]

127. Ding, C.; Yu, H. MiR-let-7e inhibits invasion and magration and regulates HMGB1 expression in papillary thyroid carcinoma. Biomed Pharmacother 2019, 110, 528-536. [CrossRef]

128. Jia, M.; Shi, Y. MicroRNA-146b-5p as an oncomiR promotes papillary thyroid carcinoma development by targeting CCDC6. Cancer Lett. 2019, 443, 145-156. [CrossRef] 
129. Li, X.; Tian, Y. CircNUP214 sponges miR-145 to promote the expression of ZEB2 in thyroid cancer cells. Biochem. Biophys. Res. Commun. 2018, 507, 168-172. [CrossRef]

130. Xia, F.; Chen, Y. Long Noncoding RNA HOXA-AS2 Promotes Papillary Thyroid Cancer Progression by Regulating miR-520c-3p/S100A4 Pathway. Cell Physiol. Biochem. 2018, 50, 1659-1672. [CrossRef]

131. Jiang, L.; Wu, Z. LncRNA HOXA-AS2 Facilitates Tumorigenesis and Progression of Papillary Thyroid Cancer by Modulating the miR-15a-5p/HOXA3 Axis. Hum. Gene Ther. 2019, 30, 618-631. [CrossRef]

132. Yu, C.; Zhang, L. MicroRNA-146b-3p Promotes Cell Metastasis by Directly Targeting NF2 in Human Papillary Thyroid Cancer. Thyroid 2018, 28, 1627-1641. [CrossRef] [PubMed]

133. Wang, M.; Chen, B. CircRNA circ-ITCH suppresses papillary thyroid cancer progression through miR-22-3p/CBL/ß-catenin pathway. Biochem. Biophys. Res. Commun. 2018, 504, 283-288. [CrossRef] [PubMed]

134. Zhao, L.; Zhang, X. Matrine inhibits TPC-1 human thyroid cancer cells via the miR-21/PTEN/Akt pathway. Oncol. Lett. 2018, 16, 2965-2970. [CrossRef] [PubMed]

135. Li, D.; Cui, C. Long non coding RNA UCA1 promotes papillary thyroid cancer cell proliferation via miR 204 mediated BRD4 activation. Mol. Med. Rep. 2018, 18, 3059-3067. [CrossRef] [PubMed]

136. Wu, W.J.; Yin, H. Long noncoding RNA LINC00313 modulates papillary thyroid cancer tumorigenesis via sponging miR-4429. Neoplasma 2018, 65, 933-942. [CrossRef]

137. Huang, Y.; Yu, S. MicroRNA-222 Promotes Invasion and Metastasis of Papillary Thyroid Cancer Through Targeting Protein Phosphatase 2 Regulatory Subunit B Alpha Expression. Thyroid 2018, 28, 1162-1173. [CrossRef]

138. Zhang, H.; Cai, Y. LncRNA BISPR promotes the progression of thyroid papillary carcinoma by regulating miR-21-5p. Int. J. Immunopathol. Pharmacol. 2018, 32, 2058738418772652. [CrossRef]

139. Feng, K.; Liu, Y. Long noncoding RNA PVT1 enhances the viability and invasion of papillary thyroid carcinoma cells by functioning as ceRNA of microRNA-30a through mediating expression of insulin like growth factor 1 receptor. Biomed. Pharmacother 2018, 104, 686-698. [CrossRef]

140. Zhang, H.; Cai, Y. Long noncoding RNA NEAT1 regulate papillary thyroid cancer progression by modulating miR-129-5p/KLK7 expression. J. Cell Physiol. 2018, 233, 6638-6648. [CrossRef]

141. Jiang, K.; Li, G. Plasma Exosomal miR-146b-5p and miR-222-3p are Potential Biomarkers for Lymph Node Metastasis in Papillary Thyroid Carcinomas. Onco. Targets Ther. 2020, 13, 1311-1319. [CrossRef]

142. Xu, C.B.; Liu, X.S. microRNA-539 functions as a tumor suppressor in papillary thyroid carcinoma via the transforming growth factor $\beta 1 /$ Smads signaling pathway by targeting secretory leukocyte protease inhibitor. J. Cell Biochem. 2019, 120, 10830-10846. [CrossRef] [PubMed]

143. Chen, Z.B.; Cao, W.L. MIR22HG inhibits cell growth, migration and invasion through regulating the miR-24-3p/p27kip1 axis in thyroid papillary carcinomas. Eur. Rev. Med. Pharmacol. Sci. 2019, 23, 5851-5862. [PubMed]

144. Gong, Y.; Wu, W. MiR-26a inhibits thyroid cancer cell proliferation by targeting ARPP19. Am. J. Cancer Res. 2018, 8, 1030-1039. [PubMed]

145. Qiu, K.; Xie, Q. miR-98-5p promotes apoptosis and inhibits migration and cell growth in papillary thyroid carcinoma through Bax/Caspase-3 by HMGA2. J. Clin. Lab. Anal. 2020, 34, e2304. [CrossRef] [PubMed]

146. Zhou, S.L.; Tang, Q.L. MiR-296-5p suppresses papillary thyroid carcinoma cell growth via targeting PLK1. Eur. Rev. Med. Pharmacol. Sci. 2019, 23, 2084-2091. [PubMed]

147. Fan, X.; Zhao, Y. miR-451a inhibits cancer growth, epithelial-mesenchymal transition and induces apoptosis in papillary thyroid cancer by targeting PSMB8. J. Cell Mol. Med. 2019, 23, 8067-8075. [CrossRef]

148. Pan, X.M.; He, X.Y. MiR-630 inhibits papillary thyroid carcinoma cell growth, metastasis, and epithelialmesenchymal transition by suppressing JAK2/STAT3 signaling pathway. Eur. Rev. Med. Pharmacol. Sci. 2019, 23, 2453-2460.

149. Haddad, R.; Nasr, C. NCCN Guidelines Insights Thyroid Carcinoma, Version 2.2018. J. Natl. Compr. Cancer Netw. 2018, 16, 1429-1440. [CrossRef] 
150. Celano, M.; Rosignolo, F. MicroRNAs as Biomarkers in Thyroid Carcinoma. Int. J. Genom. 2017, 2017, 6496570. [CrossRef]

151. Zarkesh, M.; Zadeh-Vakili, A. Altered Epigenetic Mechanisms in Thyroid Cancer Subtypes. Mol. Diagn Ther. 2018, 22, 41-56. [CrossRef] [PubMed]

Publisher's Note: MDPI stays neutral with regard to jurisdictional claims in published maps and institutional affiliations.

(C) 2020 by the authors. Licensee MDPI, Basel, Switzerland. This article is an open access article distributed under the terms and conditions of the Creative Commons Attribution (CC BY) license (http://creativecommons.org/licenses/by/4.0/). 